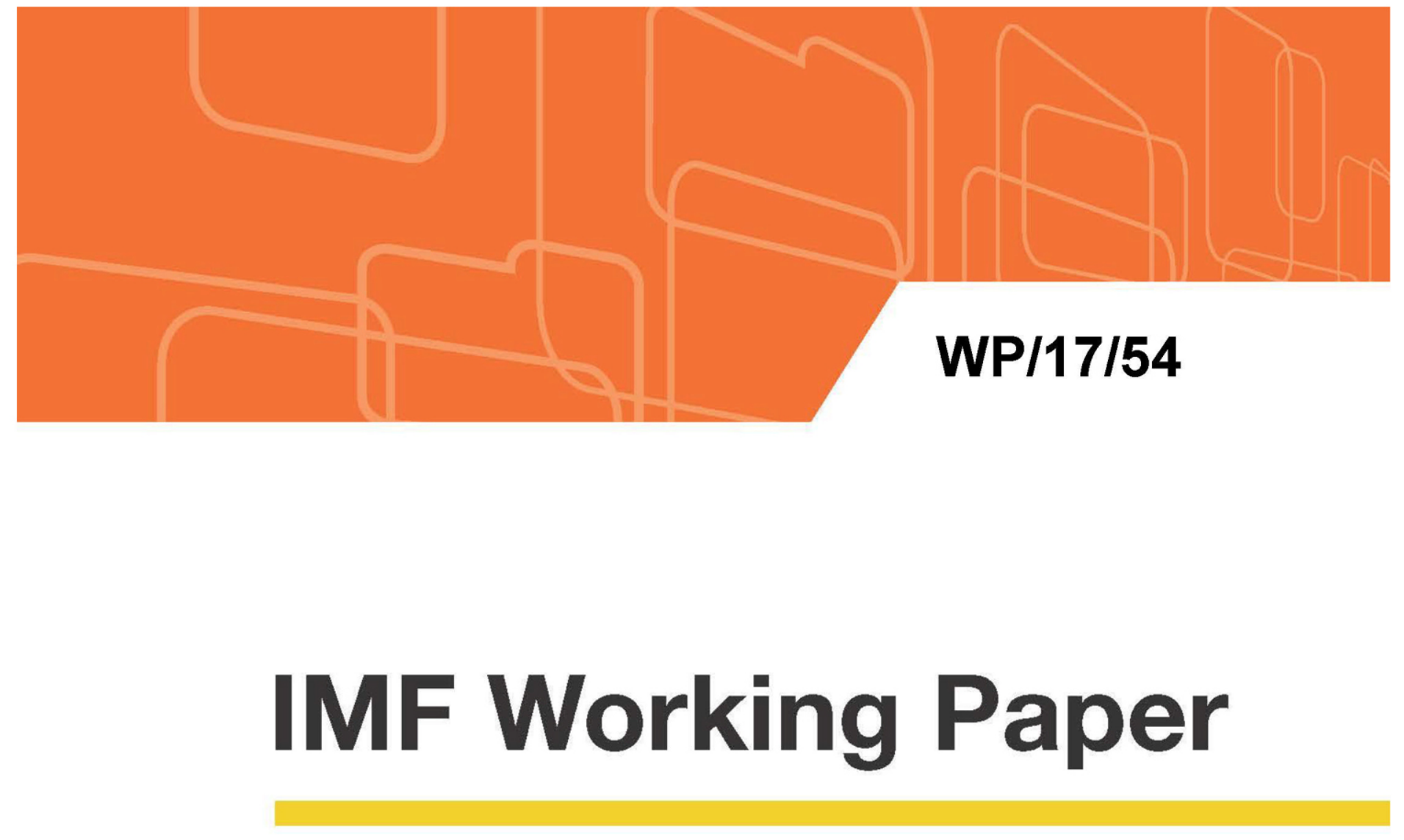

\title{
Labor Force Participation in Chile: Recent Trends, Drivers, and Prospects
}

by Patrick Blagrave and Marika Santoro

IMF Working Papers describe research in progress by the author(s) and are published to elicit comments and to encourage debate. The views expressed in IMF Working

Papers are those of the author(s) and do not necessarily represent the views of the IMF, its Executive Board, or IMF management.

(C) 2017 International Monetary Fund

$\mathrm{WP} / 17 / \mathrm{xx}$

I N T E R N A T I O N A L M O N E TAR Y F U N D 


\section{WP/17/54}

\section{IMF Working Paper}

\section{Labor Force Participation in Chile: Recent Trends, Drivers, and Prospects}

by Patrick Blagrave and Marika Santoro

IMF Working Papers describe research in progress by the author(s) and are published to elicit comments and to encourage debate. The views expressed in IMF Working Papers are those of the author(s) and do not necessarily represent the views of the IMF, its Executive Board, or IMF management.

(C) 2017 International Monetary Fund 


\title{
IMF Working Paper
}

Western Hemisphere Department

\section{Labor Force Participation in Chile: Recent Trends, Drivers, and Prospects Prepared by Patrick Blagrave and Marika Santoro ${ }^{1}$}

Authorized for distribution by Stephan Danninger

February 2017

\section{IMF Working Papers describe research in progress by the author(s) and are published to elicit comments and to encourage debate. The views expressed in IMF Working Papers are those of the author(s) and do not necessarily represent the views of the IMF, its Executive Board, or IMF management.}

\begin{abstract}
Gains in labor force participation rates in Chile have slowed in recent years. We examine their determinants using a cohort-model analysis. Allowing for both age- and cohort-specific effects in the context of a seemingly unrelated regression equations (SURE) approach, we find that age factors play an important role in determining participation decisions, especially for males. For females, we find that strong positive time trends dominate the downward pressure from demographics, although those trends have recently dissipated. In addition, we find that both cohort effects and the business cycle shape participation decisions. Using our cohort-based analysis, we construct projections of participation rates, which suggest population aging will put downward pressure on labor inputs, and thus potential output, in coming years. Further increases in female labor force participation - supported by policiescould more than offset the downward pressure from demographics.
\end{abstract}

JEL Classification Numbers: J08, J11, J21.

Keywords: Labor force partipation, female labor force participation, potential output.

Authors’ E-Mail Address: PBlagrave@imf.org, MSantoro@imf.org

\footnotetext{
${ }^{1}$ The authors would like to thank Stephan Danninger, Jorge Roldos, and the participants of seminars at the Central Bank of Chile for their comments.
} 


\section{CONTENTS}

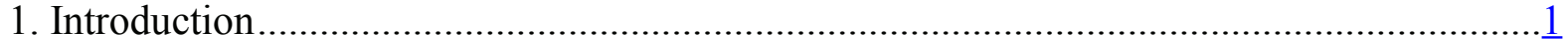

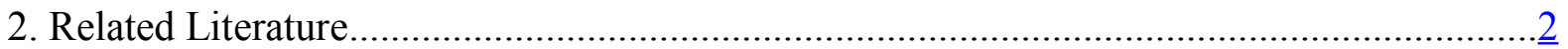

3. Potential Growth and Labor Supply Developments ..................................................... $\underline{3}$

4. Estimating Determinants of Labor Force Participation Rates ........................................

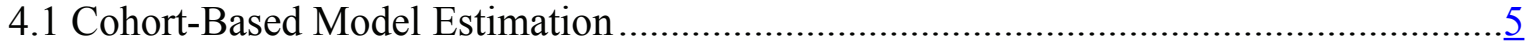

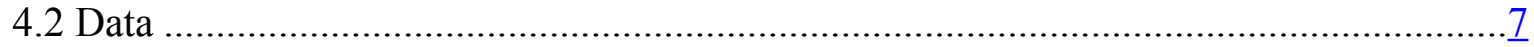

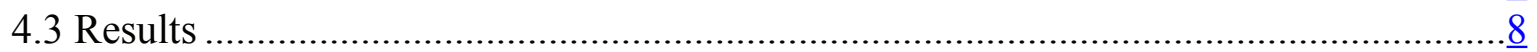

4.3.1 Age-Specific Factors ............................................................................. 11

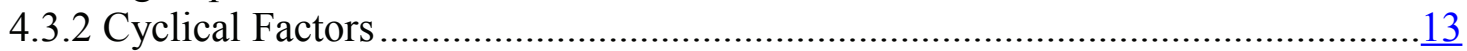

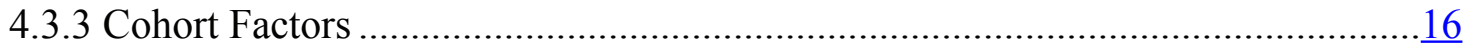

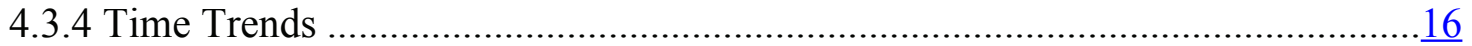

5. Projection Scenarios............................................................................................ 17

6. Concluding Remarks and Policy Discussion ......................................................... 19

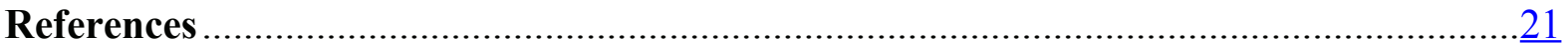




\section{Introduction}

Chile has experienced a sharp growth slowdown. After peaking at nearly 6 percent in 2011, annual GDP growth has fallen to about 2 percent in recent years. Understanding what is driving this slowdown is of critical importance to gauging Chile's medium-term outlook. This was the motivation for a companion paper (Blagrave and Santoro, 2016), where we find that a substantial part of the growth slowdown has been structural, with weak capital accumulation and slowing labor-input growth explaining more than two thirds of the decline in potential growth (50 and 20 percent of the total, respectively). ${ }^{1}$ Factors behind low investment growth have been investigated elsewhere (IMF, 2015; Albagli and Luttini, 2015; Blagrave and Santoro, 2016). Our goal in this paper is to better understand the role of declining labor-input growth and, in particular, the role of labor force participation and demographic trends.

After increasing steadily throughout much of the post-2000 period, labor force participation rates in Chile began to level off in 2011-12. The strong increase and subsequent slowdown in aggregate labor force participation is mostly due to changes in the female participation rate, which increased from around 35 percent in 2000 to nearly 50 percent in 2011 and has since leveled off. In contrast, male labor force participation has been stagnant for more than a decade.

In the context of these stylized facts, our contribution is to investigate the determinants of the changing participation rates in Chile using a cohort model similar to Fallick and Pingle (2007) and Balleer, Gomez-Salvador and Turunen (2014). Our analysis focuses on the role of age, business cycle, and cohort-specific effects in driving participation decisions for male and female workers. Our findings suggest an important relationship between age and participation rates - labor supply over the life cycle resembles an inverted U shape, with workers of both genders supplying more labor during the prime working ages of 35-54. In addition, we find that the business cycle influences the participation of non-prime aged males, with both younger and older workers supplying less labor when there is more economic slack-however, when controlling for enrollment in tertiary-level education, this effect disappears for younger workers, suggesting that enrollment is pro-cyclical and that young people choose to attain more education when job prospects are less favorable. The business cycle effect is even more pronounced for females, irrespective of age, possibly suggesting that women are more likely to be marginal employees or second earners.

Cohort-specific effects also shape labor supply decisions, with females born in the 1960s less likely to supply labor throughout their lives. Finally, time trends capture a large portion of the increase in female participation rates since the late 1990s. Even after controlling for changes in enrollment in tertiary education, strong time trends do not disappear, signaling that they likely capture the effects of policies or other cultural factors, such as a gradual improvement in population-wide perceptions of female work outside the home and increased availability of childcare facilities. The exact contribution of these factors remains an open question worthy of future research.

Having estimated the cohort model, we use the results to develop projection scenarios of future participation-rate dynamics based on expected demographic changes, which we then

\footnotetext{
${ }^{1}$ The causes for lower potential growth in Chile differ from those in most other emerging economies, where low productivity growth - the residual from a Cobb-Douglas growth accounting - has been the major source of weakness (IMF, 2015).
} 
use to estimate the impact of demographics on potential growth in the medium term. We present several scenarios to evaluate the sensitivity of growth estimates to changes in the labor force participation rate. First, in a baseline absent any policy change, we present only the effect on participation rates of projected demographic factors (that is, population aging). In this scenario, participation rates would be $1 / 5$ of a percentage point lower by 2021 . Then, we present two alternatives, one where the rate of female labor force participation continues to rise, in line with recent historical trends, while that of men remains at the current elevated level, and a second scenario which adds a positive trend in male participation rates (increasing for older workers). In the second, most optimistic scenario in which participation rates of both males and females continue on the slight upward trend observed in the past, potential growth could be higher by up to $1 / 4$ percentage points in the medium term, relative to our baseline scenario.

The remainder of the paper is organized as follows. Section 2 provides an overview of related literature, while section 3 describes the evolution of past potential growth and the impact of changes in labor force participation on the recent slowdown. Then, section 4 presents the cohort model and the main results. Section 5 focuses on the medium-term projection scenarios of potential growth and section 6 concludes.

\section{$2 \quad$ Related Literature}

Our work relates to several papers on the determinants of participation rates in Chile. Marcel and Naudon (2016) analyzes transition probabilities between labor states in Chile and highlights how participation rates have increased, especially for women, in the past decade, noting also that growth has recently slowed. Pardo (1988) documents the historical evolution of male and female participation rates in Chile over the period from 1907-1982, noting that the dynamics of aggregate participation rates tend to be associated with demographics, the business cycle, and educational attainment levels.

Going a step further, Larrañega (2006) considers a longer sample (through 2003) and estimates probit models to gauge the probability of labor force participation by females in relation to a host of proximate causes. Focusing only on females aged 25-45 to omit the effects of life-cycle labor supply dynamics, the author finds that education and fertility are important factors related to female labor supply (increasing in the former, and decreasing in the latter). In addition, the impact of fertility and number of children on the participation decision depends on marital status. Finally, overall family income and head-of-household status (male vs. female) play a role in the labor supply decision as well-females who are the heads of their household tend to supply more labor.

Ferrada and Espina (2010) conduct a similar analysis, but for different regions in Chile, and find significant dispersion in female labor-supply decisions and the importance of determinants across regions. The aforementioned studies share at least one common thread-there is a large gap between female participation rates in Chile, and those in other peer countries, which has been referred to as the 'Chilean exception' or the 'Chilean gender paradox.'

Studies by Fort and others (2007) and Contreras, Hurtado and Sara (2012) find that this gap is largely a reflection of perceptions about the role of women in the home evidence in these papers suggests that women in Chile have a more negative view of work outside the

CInternational Monetary Fund. Not for Redistribution 
home than do counterparts in other countries.

Similar to these papers, our work also finds that demographic and cyclical factors are important for aggregate labor force participation. We also document the existence of a structural gap between male and female participation but we find significant increasing trends in female participation that are not explained by cohort effects or demographic changes, but could be related to changes in cultural factors or policies. Different from previous literature, exploiting mainly micro-data, we do not find that enrollment in higher education affects aggregate female labor force participation but only male participation for certain age classes.

\section{Potential Growth and Labor Supply Developments}

Real growth in Chile has decelerated since 2011 and has been particularly lackluster in the last two years (Figure 1).

Figure 1: Real GDP growth

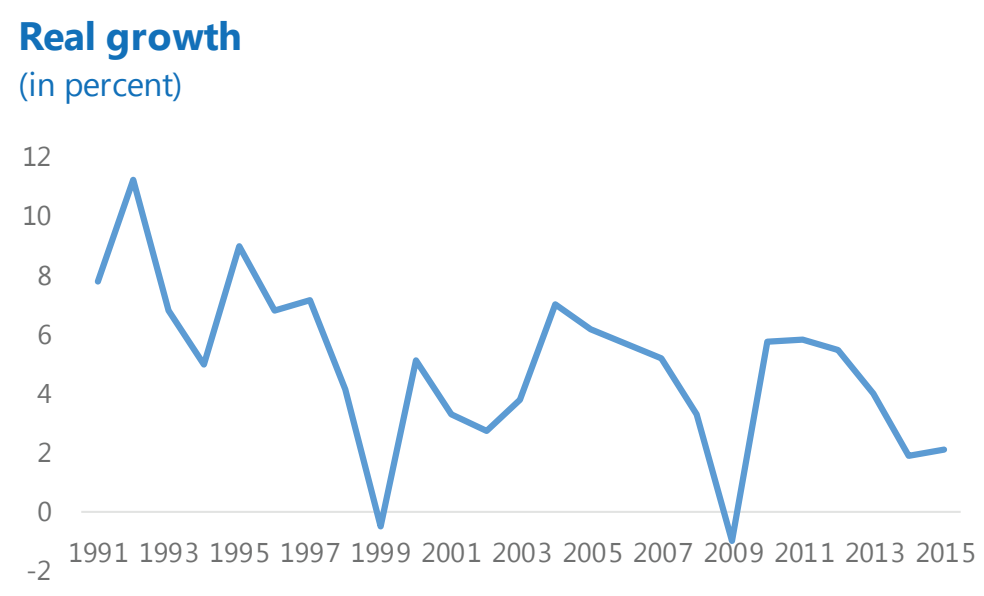

Source: IMF World Economic Outlook. In percent

Examining the experience of the mining and non-mining sectors separately, Blagrave and Santoro (2016) show that structural factors have played an important role in the observed slowdown. Among the factors responsible for this decline, in the mining sector issues related to the gradual deterioration in the quality of ore grade at aging mines has impaired totalfactor productivity (TFP) growth, in turn requiring persistently high investment to maintain production levels (this is closely related to concepts discussed in Aguirregabiria and Luengo, 2015). In the case of the non-mining sectors of Chile's economy, slower capital accumulation and TFP growth explains slightly above 75 percent of the slowdown in potential growth, relative to its value in 2011. Slower labor-input growth accounts for the remainder of the decline.

While issues related to TFP and capital accumulation slowdown have been investigated (Corbo, 2014; Albagli and Luttini, 2015; IMF, 2015; Blagrave and Santoro, 2016), the contribution of labor inputs to potential growth has received less attention, which motivates the work presented in this paper. Figure 2 breaks the evolution of the labor input into 
its component parts and shows an important role for declines in average hours worked in depressing labor-input growth rates.

Figure 2: Labor input growth: A decomposition

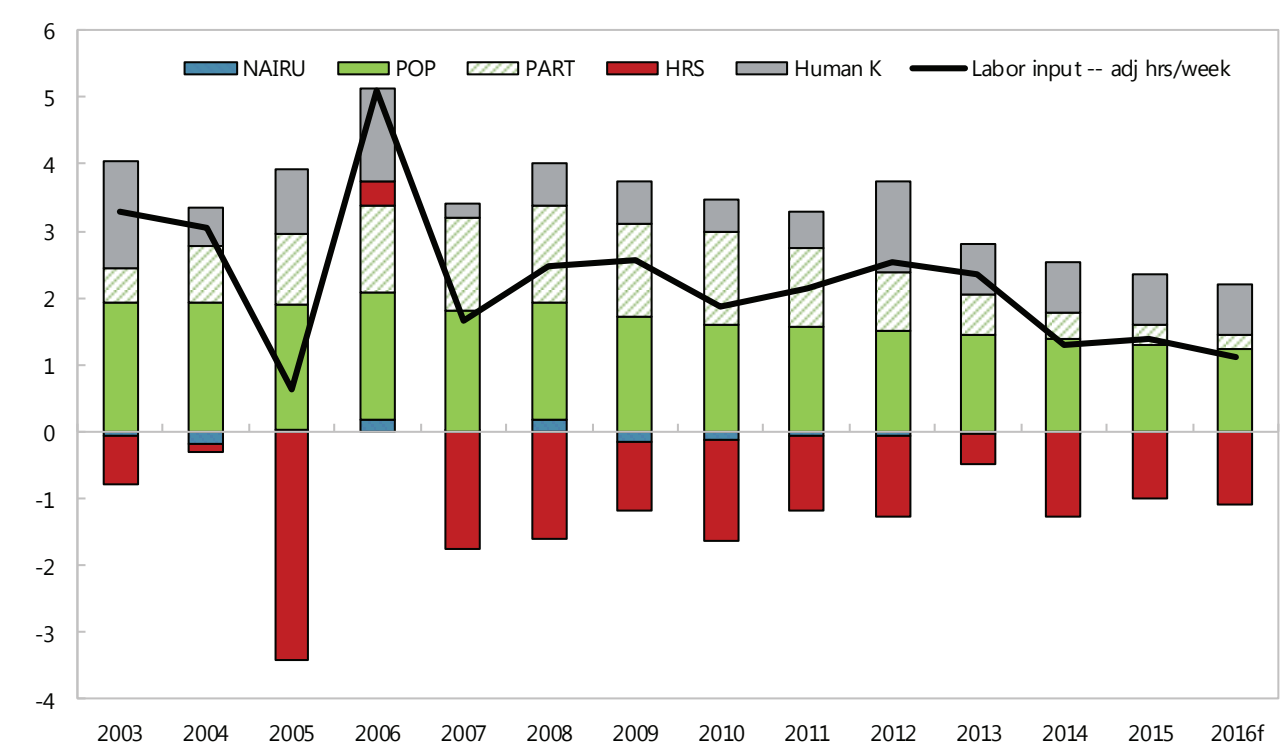

Source: Blagrave and Santoro, 2016. In percentage points. Labor input growth is calculated from population growth adjusted for hours worked and human capital growth

On aggregate, the trend towards shorter work weeks is being offset by steady increases in human capital, while the NAIRU has been quite stable over the sample period. For their part, population growth rates are slowing, further weighing down on labor-force growth. Finally, and perhaps most relevant to the recent deceleration in labor-input growth, is the shift in participation rates since 2011. Indeed, steady increases in participation rates over much of the last two decades have lifted the growth rate of labor in the Chilean economy - as rates have leveled off in recent years, labor has contributed less to potential growth.

Delving further into this, we see that labor force participation rates in Chile were on an upward trend relative to the rest of the region during the first decade of the 2000s. For men, labor force participation rates have been stagnant for several decades, though flattening trends for participation have been more pronounced at young ages - possibly as a result of higher enrollment in tertiary education - and at prime age (Figure 3). Comparing the Chilean experience to those in other countries, we see that participation rates have historically been very close to, or higher than OECD averages, in the case of males (Figure 4).

For women, participation rates have trended steadily higher starting in the late 1990s. Once again putting historical female labor force participation rates in Chile in context, these have lagged behind OECD averages (52 percent), a phenomenon that has been documented elsewhere (for example, Contreras, Hurtado, and Sara (2012))-however, more recently, participation among females in Chile has been similar to that in other Latin American countries, though a considerable gap remains relative to top performers in the region (Figure 5). 
Figure 3: Labor force participation rate

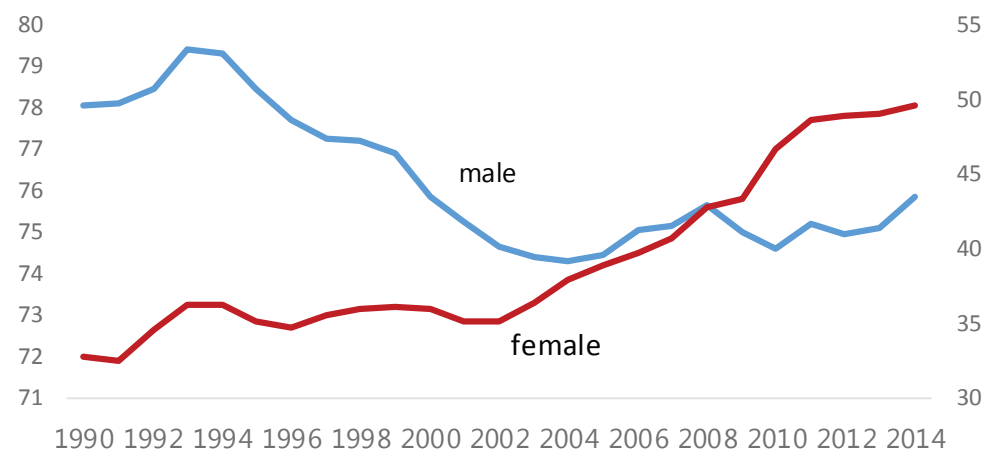

Source: ILO, Key Indicators of the Labor Market (KILM). In percent. The data are taken from official labor force data and harmonized across countries.

Focusing on the more recent period, during the first decade of the 2000s female participation rates closed 30 percent of the gap with men but remain below average levels in OECD countries. As will become clear later in the paper, this upward trend in female participation is difficult to explain using readily observable data - rather, it seems to relate to a shift in policies or preferences regarding formal employment and work outside of the home more generally.

Among men, only workers 65 and older have showed signs of increasing participation, as retirement is being postponed in line with longer lifespans, although even this positive trend among older male workers has recently slowed (Figure 6). For women, all age groups, but in particular those age 24 to 54, have displayed positive trends in their supply of labor during the 2000s, with a slowdown starting in 2011.

In the next section, we investigate the main drivers of male and female participation rates. The goal is to gain a firmer understanding of what has contributed to stagnating male participation rates, and steady increases and a more recent stabilization in the participation of women.

\section{Estimating Determinants of Labor Force Participa- tion Rates}

\subsection{Cohort-Based Model Estimation}

In this section, we present an empirical model that decomposes the movements in labor force participation into determinants driven by: (i) the aging of the population; (ii) cohort effects; (iii) time trends within age groups; and (iv) the business cycle. By using the estimated contributions of these drivers and the projected future evolution of Chile's demographics, we are able to explain a portion of past dynamics of labor force participation rates, as well as assess the likely future change in participation rates and their impact on potential growth 
Figure 4: Labor force participation rate by age groups

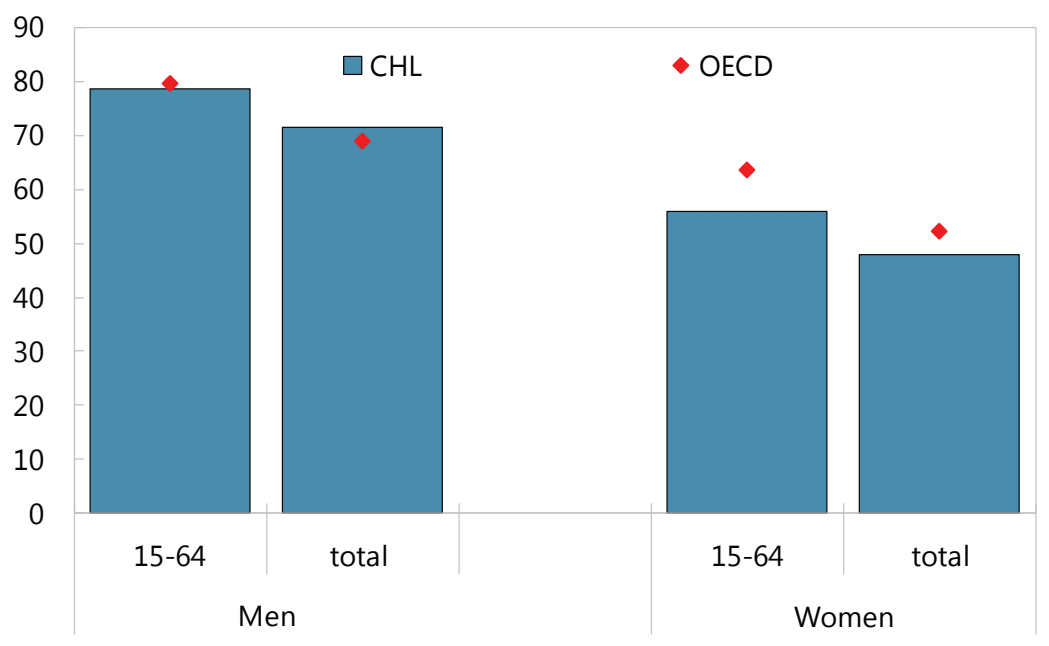

Source: OECD Labor Force Statistics, 2015. OECD average computed by source.

(an exercise conducted in the next section).

First, since determinants of labor force participation vary over the life cycle, and by gender, we decompose aggregate participation rates into those of different age and gender groups. Our cohort-based model is similar to Fallick and Pingle (2007) and Balleer, Gomez-Salvador and Turunen (2014).

For each age group $a$, gender $g$, in year $t$, we express labor force participation (LFP) as a function of age-specific factors $(\alpha)$, birth cohort $(I)$, business cycle (cycle), and other factors $(Z)$ including a time trend. We estimate the following equation using a seemingly unrelated regression equations (SURE) approach:

$$
\ln L F P_{a, j, t}=\alpha_{a, j}+\frac{1}{n_{a}} \sum_{i=1925}^{1990} \beta_{i, j} I_{a, t}+\sum_{z=0}^{1} \gamma_{a, j} c y c l e_{t-z}+\delta_{a, j} Z_{a, j, t}+\epsilon_{a, j, t}
$$

The age and gender-specific intercept $(\alpha)$ captures the average labor force participation rate for each age group. The idea is that the labor supply decision varies across an individual's life cycle - for instance, at the margin, younger people are more likely to acquire skills than to supply labor, relative to older age groups, which depresses their participation rate. We also estimate the contribution of the unobservable cohort effects $(I)$ for each birth year of the labor force in the sample. This effect accounts for changing cultural and behavioral attitudes towards labor supply and corrects the age-specific intercept. This correction implies that the average LFP of an age $a$ individual born in 1950 can be different from the average LFP of an age $a$ individual born in 1980, for instance. As such, cohort effects shift the whole life-cycle participation profile up or down, depending on the birth year of a cohort. For each age group, to obtain the average cohort effect, the cohort coefficient $\beta$ is divided by the number of cohorts $n_{a}$ included in any age group. 
Figure 5: Female labor force participation rate in Latin America (2014)

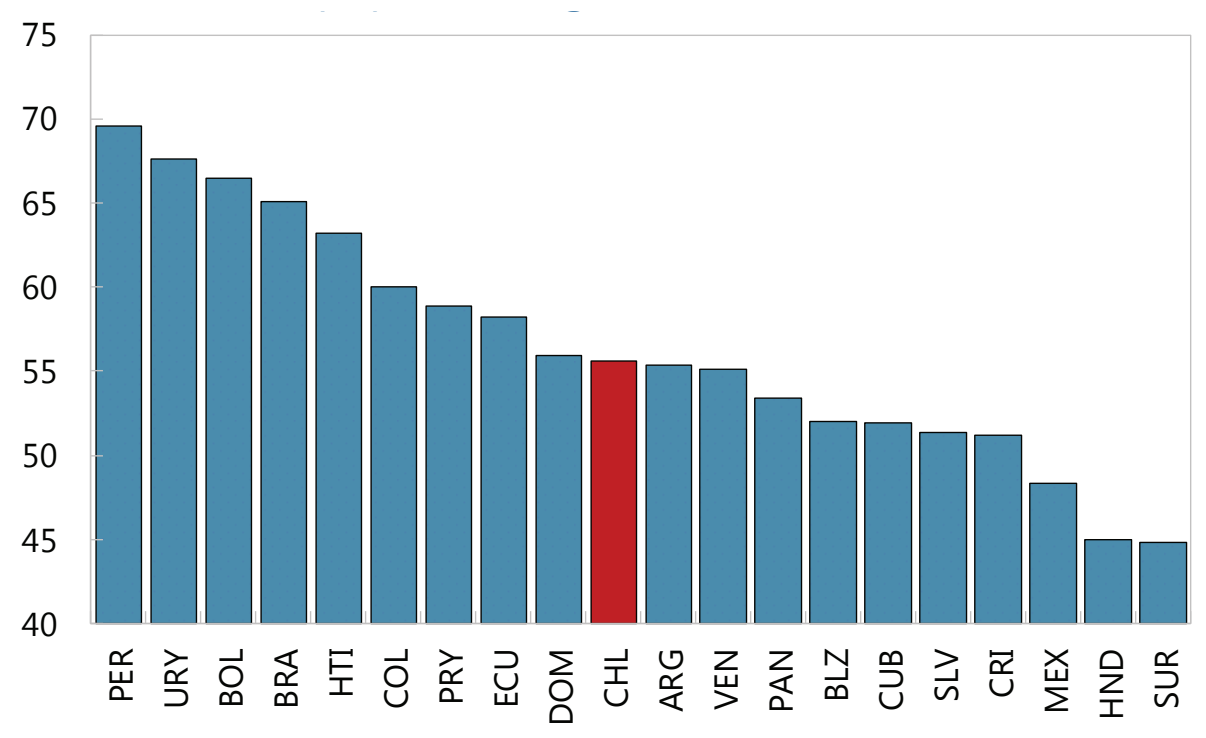

Sources: World Bank WDI.

The business cycle can be another determinant of individuals' decisions to participate in the labor market. For instance, good economic conditions can be seen as increasing the probability of finding a job and therefore incentivizing searching. These effects can also change according to age and gender.

In the case of Chile, we do not have specific time-series data by age and gender on some structural variables that can affect labor market participation, such as enrollment in higher education or fertility rates. For this reason, to capture changes in those and other types of structural factors, we include also a linear and a quadratic time trend. Time trends also control for policy and social changes not captured by our other explanatory variables. ${ }^{2}$

\subsection{Data}

The sample consists of five age groups (15-24, 25-34, 35-54, 55-64, 65+) for each gender from 1990 to 2014. Labor market data at yearly frequency are compiled by the Chilean National Institute of Statistics (INE) and the ILO while the other data on fertility, school enrollment and population projections are from the World Development Indicators and United Nations Population and Development Database. Data on labor force participation and employment are then adjusted for the change in the labor force survey introduced between 2009 and 2010. Using 2010 as an overlapping year between the two surveys, the level of the participation rate is spliced backwards until 1990, applying the rate of change in the series based on the old survey. The cyclical position of the economy is proxied by the employment gap (or the deviation of employment from its long-run trend constructed using an Hodrick-Prescott

\footnotetext{
${ }^{2}$ The role of these omitted variables is likely non-trivial, as policies such as mandatory unemployment insurance for formal workers and an enhanced solidarity pillar for pensions can play an important role in shaping participation decisions in the formal labor market.
} 
Figure 6: Labor force participation rate by age groups

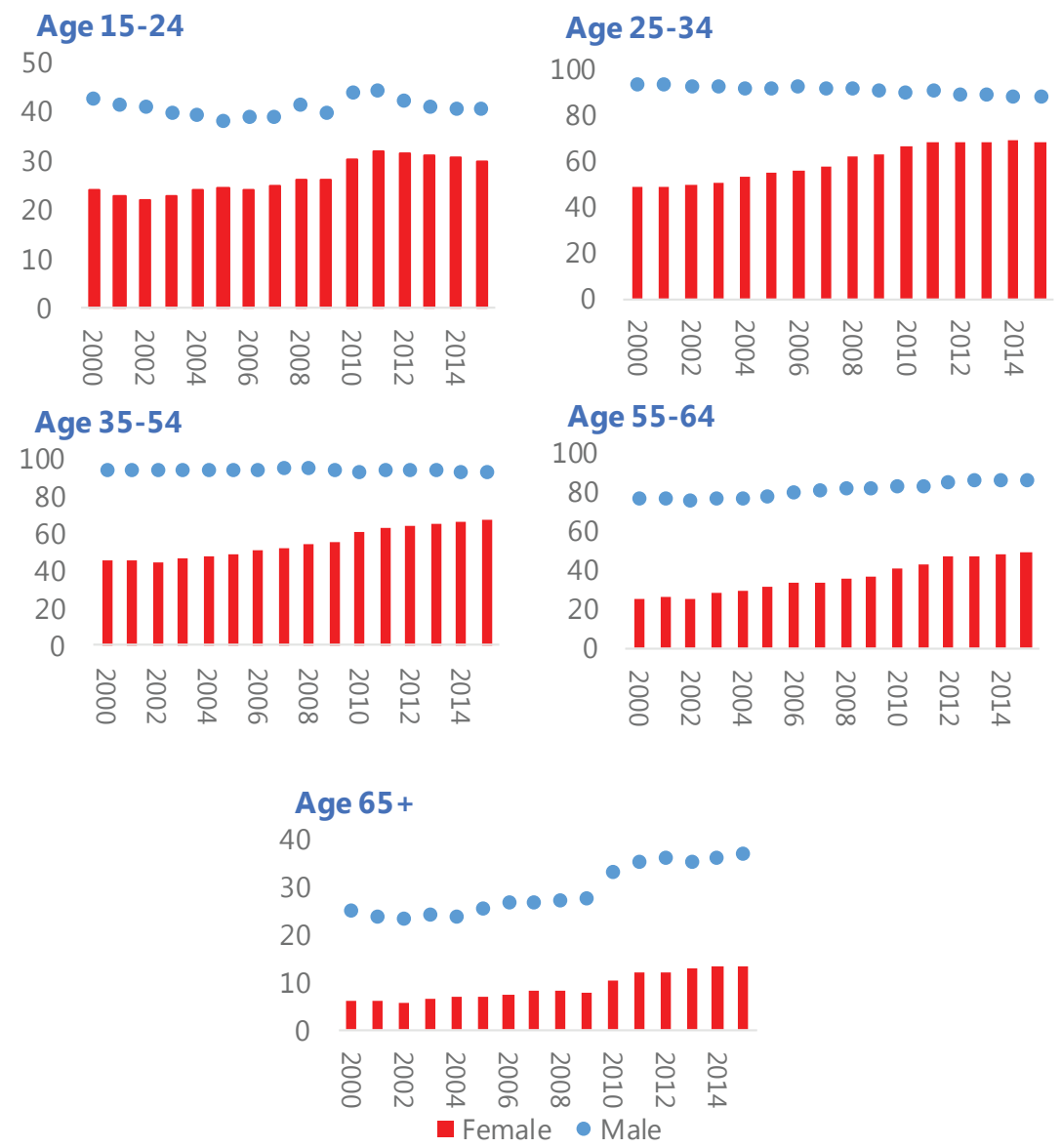

Source: ILO, Key Indicators of the Labour Market (KILM). In percent

filter).

Cohorts born after 1990 entered the labor force only during or after the global financial crisis, making it difficult to distinguish the negative effect of the crisis from any potential cohort-specific trends for this group. To mitigate this end- and starting-point problem, the equation (1) is also estimated allowing for the cohort effect of those born after 1988 and before 1920 to equal the average of that for the adjacent five cohorts. The results are robust to this alternative specification.

\subsection{Results}

In this section, we discuss the results of the estimation of the system of equations (1). Table 1 and Table 2 display the results respectively for men and women and the five age groups in the baseline specification described in the previous section. Table 3 and Table 4 show figures in the case of an alternative specification. 
Table 1: Male labor force participation: a cohort model estimation

\begin{tabular}{|c|c|c|c|c|c|}
\hline VARIABLES & $\begin{array}{c}(1) \\
\text { lfpr15 }\end{array}$ & $\begin{array}{c}(2) \\
\text { lfpr } 25\end{array}$ & $\begin{array}{c}(3) \\
\text { lfpr35 }\end{array}$ & $\begin{array}{c}(4) \\
\text { lfpr55 }\end{array}$ & $\begin{array}{c}(5) \\
\text { lfpr65 }\end{array}$ \\
\hline trend & $-0.024^{* *}$ & -0.001 & -0.001 & $0.009^{*}$ & $-0.024^{* *}$ \\
\hline trend2 & $0.001+$ & -0.000 & 0.000 & 0.000 & $0.001^{* *}$ \\
\hline cycle & $0.999 *$ & 0.006 & -0.054 & 0.307 & $1.668^{* *}$ \\
\hline $15 \_1975$ & 0.048 & & & & \\
\hline $15 \_1980$ & -0.034 & & & & \\
\hline $15 \_1985$ & -0.048 & & & & \\
\hline $15 \_$1990 & -0.002 & & & & \\
\hline $25 \_1965$ & & $0.028^{* *}$ & & & \\
\hline $25 \_1970$ & & -0.002 & & & \\
\hline $25 \_1975$ & & $0.020^{* *}$ & & & \\
\hline $25 \_1980$ & & 0.001 & & & \\
\hline $35 \_1955$ & & & $0.030^{* *}$ & & \\
\hline $35 \_1960$ & & & 0.000 & & \\
\hline $35 \_1965$ & & & $-0.005^{*}$ & & \\
\hline $35 \_1970$ & & & 0.001 & & \\
\hline $55 \_1935$ & & & & $0.053^{*}$ & \\
\hline $55 \_1940$ & & & & $-0.035^{*}$ & \\
\hline $55 \_1945$ & & & & 0.025 & \\
\hline $55 \_1950$ & & & & $-0.042^{*}$ & \\
\hline $65 \_1925$ & & & & & -0.001 \\
\hline $65 \_1930$ & & & & & -0.065 \\
\hline $65 \_1935$ & & & & & $-0.165 * *$ \\
\hline $65 \_1940$ & & & & & $-0.123^{* *}$ \\
\hline Constant & $4.015^{* *}$ & $4.549^{* *}$ & $4.550^{* *}$ & $4.250^{* *}$ & $3.497 * *$ \\
\hline R-squared & 0.949 & 0.979 & 0.974 & 0.923 & 0.959 \\
\hline
\end{tabular}

Note: Confidence level $\left(* *=99\right.$ percent, ${ }^{*}=95$ percent,$+=90$ percent $)$. 
Table 2: Female labor force participation: a cohort model estimation

\begin{tabular}{|c|c|c|c|c|c|}
\hline & (1) & $(2)$ & $(3)$ & (4) & $(5)$ \\
\hline VARIABLES & lfpr15 & lfpr25 & lfpr35 & lfpr55 & lfpr65 \\
\hline trend & -0.006 & $0.019^{* *}$ & $0.019^{* *}$ & -0.001 & -0.007 \\
\hline trend2 & 0.001 & 0.000 & 0.000 & $0.001^{* *}$ & $0.001^{*}$ \\
\hline cycle & $2.247^{* *}$ & -0.038 & $0.641^{*}$ & $1.691^{* *}$ & $4.079^{* *}$ \\
\hline $15 \_1975$ & 0.065 & & & & \\
\hline $15 \_1980$ & -0.049 & & & & \\
\hline $15 \_1985$ & -0.060 & & & & \\
\hline 15 1990 & -0.028 & & & & \\
\hline $25 \_1965$ & & 0.022 & & & \\
\hline $25 \_1970$ & & $-0.045^{*}$ & & & \\
\hline $25 \_1975$ & & -0.020 & & & \\
\hline $25 \_1980$ & & 0.001 & & & \\
\hline $35 \_1955$ & & & $-0.038+$ & & \\
\hline $35 \_1960$ & & & $-0.069 * *$ & & \\
\hline $35 \_1965$ & & & $-0.043^{* *}$ & & \\
\hline $35 \_1970$ & & & 0.009 & & \\
\hline $55 \_1935$ & & & & 0.051 & \\
\hline $55 \_1940$ & & & & $-0.062+$ & \\
\hline $55 \_1945$ & & & & 0.037 & \\
\hline $55 \_1950$ & & & & -0.045 & \\
\hline $65 \_1925$ & & & & & 0.071 \\
\hline $65 \_1930$ & & & & & 0.007 \\
\hline $65 \_1935$ & & & & & -0.056 \\
\hline $65 \_1940$ & & & & & -0.067 \\
\hline Constant & $3.259^{* *}$ & $3.731^{* *}$ & $3.758^{* *}$ & $3.148^{* *}$ & $1.793^{* *}$ \\
\hline R-squared & 0.899 & 0.990 & 0.990 & 0.986 & 0.961 \\
\hline
\end{tabular}

Note: Confidence level $\left(* *=99\right.$ percent, ${ }^{*}=95$ percent,$+=90$ percent $)$. 


\subsubsection{Age-specific factors}

The importance of the age factors (i.e. age-specific constant in each equation in system 1) is illustrated in Figure 7, which plots the levels of LFP rate by age and gender implied by the constant in each regression (different $\alpha_{a, j}$ ). The figure displays the life-cycle pattern of labor supply: low for youth, increasing during prime age, flattening later in life before decreasing as retirement age approaches. These life-cycle patterns are similar for men and women but display a gender gap along the entire life cycle.

Figure 7: Age-specific factor in LFP rate

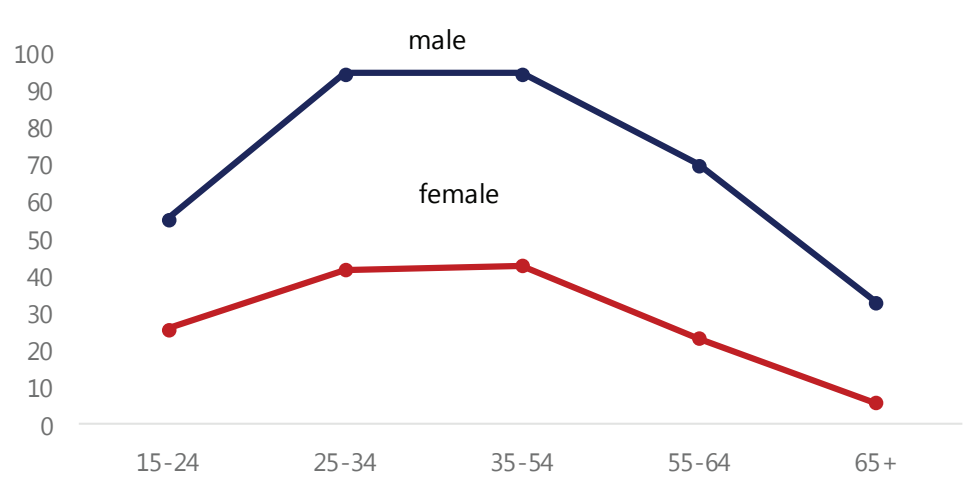

Source: IMF staff calculations. In percent

Consistent with what has been found by previous literature (Fallick and Pingle, 2007), for men, age represents a strong and significant determinant of labor force participation, explaining between 80 and 95 percent of the level of LFP at each age, at 99 percent confidence. For instance, individuals belonging to the age group 25-34 (their participation variable is marked by lfpr 25 in Table 1) are likely to participate more to the labor market than individuals belonging to the group 15-24 (lf pr 15), independently of any other characteristics. Their rate would likely be higher by nearly 40 percentage points than individuals belonging to the age group 15 to 24 .

In terms of levels, the age factors (constant) by themselves would predict a higher level of LFP for the age group 15 to 24 (about 55 percent) than the actual (41 percent in 2015, see also Figure 4), for group 25 to 34 (94 percent versus 89 percent) and to a minor extent for age group 35 to 54 (94.6 percent versus 93.4 percent). For these age groups, other factors play an important role to keep participation lower than what would be expected based on their age.

In the case of women, the age factors explain a much lower fraction of the level of LFP (between 45 and 80 percent). In addition, while in the case of men the age factor alone would predict a higher participation for prime age workers, for women the age would predict a much lower participation rate indicating that other factors have been important in keeping LFP higher, especially during the last decade.

The existence of significant age-specific LFP rates imply that the age composition of the work force is a very important determinant of the aggregate labor force participation, affecting the aggregate participation rate. More specifically, the larger the share of the population in their prime working years (25-54) the higher is aggregate participation, ceteris paribus. Of 
course, population aging has the potential to significantly reduce participation rates, as the bulk of the population ages past its prime working years.

With these results in hand, we analyze to what extent historical changes in the agedistribution of the labor force explains the trends in male and female LFP described in Section 4.1. To do this, we simulate the LFP rates implied by the age composition of the labor force, using population data and the age-specific factor $\alpha_{a, j=m, f}$. Figure 8, Panel A and B, displays the profiles for male as well as for female labor force participation.

Figure 8: Aging component of LFP rate

Panel A. Male

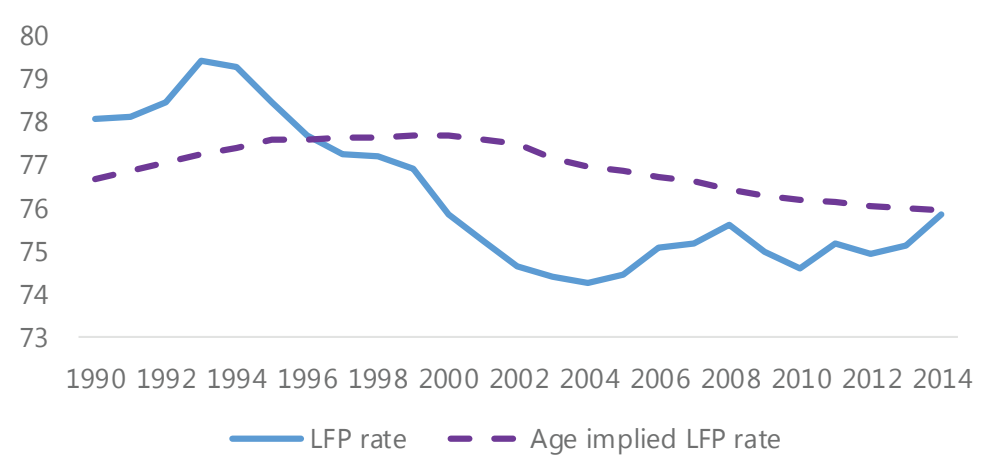

Panel B. Female

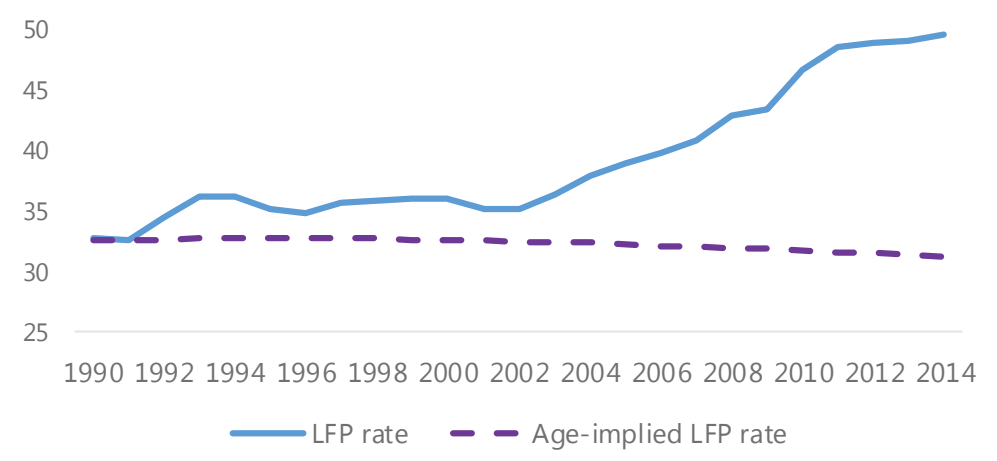

Source: IMF staff calculations. In percent. The age-implied LFP rate is calculated using the age-specific constant $\alpha$ and appyling the changes in the age composition of the population

In the case of men, the gradual change in the age distribution of the labor force towards an older population seem to imply a 1.2 percentage point reduction in LFP since the late 1990s, explaining almost all the stagnation in the LFP. By contrast, for women, aging only has a marginal role in explaining trend in LFP — as expected, given the lower predicting 
power of age factors already described. The change in the composition of the labor force predicts a fall similar to the one implied for men of just above 1 percentage point, since late 1990s. However, the LFP rate for women instead increased by 14 percentage points since the start of the 2000s. Clearly other forces dominate aging effects and are the main drivers of the recent trends. In the future, the aging of the population will imply an increased share of older workers, both for men and women, lowering the average participation rate, absent other factors, and therefore potential labor factors.

\subsubsection{Cyclical factors}

Labor force participation decisions appear to be significantly influenced by the business cycle (cycle in Table 1 and subsequent), at different ages. ${ }^{3}$ For men, participation is significantly procyclical at young and old ages, in line with previous literature. Since we do not have data on education by age and gender, in an alternative specification we add the (log) aggregate enrollment rate in tertiary education (ltert in Table 3 and subsequent) to explicitly control for changes in education enrollment over time. When we include the aggregate enrollment rate in tertiary education, the cyclical component of labor force participation at young ages becomes statistically insignificant, signaling that the decision to continue to study is also related to the cycle (Table 3 ).

For women, labor force participation is strongly procyclical, especially at young ages but also later in life, in particular at ages 65 and older. ${ }^{4}$ The inclusion of the aggregate enrollment rate in tertiary education does not change results on how participation is sensitive to the cycle, maybe indicating that in the case of women that decision is less correlated with the economic conjuncture (Table 4).

\footnotetext{
${ }^{3}$ In an alternative specification, we have used the output gap to measure the position of the economy in the cycle. Results remain robust.

${ }^{4}$ In an alternative specification, we also allow for contemporaneous as well as delayed response of participation rates to cyclical conditions. Both in the case of men and women, participation appears to react significantly only to contemporaneous conditions.
} 
Table 3: Male labor force participation: estimation, including tertiary education enrollment

\begin{tabular}{|c|c|c|c|c|c|}
\hline VARIABLES & $\begin{array}{c}(1) \\
\text { lfpr15 }\end{array}$ & $\begin{array}{c}(2) \\
\text { lfpr25 }\end{array}$ & $\begin{array}{c}(3) \\
\text { lfpr35 }\end{array}$ & $\begin{array}{c}(4) \\
\text { lfpr55 }\end{array}$ & $\begin{array}{c}(5) \\
\text { lfpr65 }\end{array}$ \\
\hline trend & -0.011 & 0.002 & -0.003 & $0.013^{*}$ & $-0.037 * *$ \\
\hline trend2 & 0.000 & $-0.000^{*}$ & 0.000 & 0.000 & $0.001^{* *}$ \\
\hline cycle & 0.638 & -0.054 & 0.004 & 0.179 & $2.055^{* *}$ \\
\hline ltert & $-0.202+$ & & & & \\
\hline $15 \_1975$ & 0.029 & & & & \\
\hline $15 \_1980$ & -0.042 & & & & \\
\hline $15 \_1985$ & $-0.081+$ & & & & \\
\hline $15 \_1990$ & -0.008 & & & & \\
\hline ltert & & -0.033 & & & \\
\hline $25 \_1965$ & & $0.024^{* *}$ & & & \\
\hline $25 \_1970$ & & -0.003 & & & \\
\hline $25 \_1975$ & & $0.015^{*}$ & & & \\
\hline $25 \_1980$ & & 0.000 & & & \\
\hline ltert & & & $0.032^{* *}$ & & \\
\hline $35 \_1955$ & & & $0.036^{* *}$ & & \\
\hline $35 \_1960$ & & & 0.002 & & \\
\hline $35 \_1965$ & & & -0.003 & & \\
\hline $35 \_1970$ & & & 0.001 & & \\
\hline ltert & & & & -0.071 & \\
\hline $55 \_1935$ & & & & $0.046^{*}$ & \\
\hline $55 \_1940$ & & & & $-0.038^{* *}$ & \\
\hline $55 \_1945$ & & & & 0.013 & \\
\hline 55 _1950 & & & & $-0.043^{*}$ & \\
\hline ltert & & & & & 0.216 \\
\hline $65 \_1925$ & & & & & 0.014 \\
\hline $65 \_1930$ & & & & & -0.041 \\
\hline $65 \_1935$ & & & & & $-0.126^{*}$ \\
\hline $65 \_1940$ & & & & & $-0.087+$ \\
\hline Constant & $4.667^{* *}$ & $4.656^{* *}$ & $4.443^{* *}$ & $4.480^{* *}$ & $2.804^{* *}$ \\
\hline R-squared & 0.953 & 0.981 & 0.981 & 0.927 & 0.963 \\
\hline
\end{tabular}

Note: Confidence level $\left(* *=99\right.$ percent, ${ }^{*}=95$ percent,$+=90$ percent $)$. 
Table 4: Female labor force participation: estimation, including tertiary education enrollment

\begin{tabular}{|c|c|c|c|c|c|}
\hline & (1) & (2) & (3) & (4) & $(5)$ \\
\hline VARIABLES & lfpr15 & lfpr25 & lfpr35 & lfpr55 & lfpr65 \\
\hline trend & -0.010 & $0.020^{*}$ & $0.029 * *$ & 0.017 & -0.023 \\
\hline trend2 & 0.001 & 0.000 & 0.000 & $0.001^{* *}$ & $0.002^{*}$ \\
\hline cycle & $2.357^{* *}$ & -0.055 & 0.387 & $1.213^{*}$ & $4.503^{* *}$ \\
\hline ltert & 0.057 & & & & \\
\hline 15 _1975 & 0.070 & & & & \\
\hline $15 \_$1980 & -0.047 & & & & \\
\hline $15 \_1985$ & -0.050 & & & & \\
\hline $15 \_1990$ & -0.026 & & & & \\
\hline ltert & & -0.009 & & & \\
\hline $25 \_1965$ & & 0.022 & & & \\
\hline $25 \_1970$ & & $-0.045^{*}$ & & & \\
\hline $25 \_1975$ & & -0.022 & & & \\
\hline $25 \_1980$ & & 0.001 & & & \\
\hline ltert & & & -0.133 & & \\
\hline $35 \_1955$ & & & $-0.062^{*}$ & & \\
\hline $35 \_$1960 & & & $-0.075^{* *}$ & & \\
\hline $35 \_$_1965 & & & $-0.055^{* *}$ & & \\
\hline 35 1970 & & & 0.011 & & \\
\hline ltert & & & & -0.251 & \\
\hline $55 \_1935$ & & & & 0.028 & \\
\hline $55 \_1940$ & & & & $-0.072^{*}$ & \\
\hline $55 \_1945$ & & & & -0.009 & \\
\hline $55 \_1950$ & & & & -0.052 & \\
\hline ltert & & & & & 0.223 \\
\hline $65 \_1925$ & & & & & 0.086 \\
\hline $65 \_1930$ & & & & & 0.031 \\
\hline $65 \_1935$ & & & & & -0.012 \\
\hline $65 \_1940$ & & & & & -0.027 \\
\hline Constant & $3.088 * *$ & $3.757^{* *}$ & $4.167^{* *}$ & $3.898 * *$ & 1.135 \\
\hline R-squared & 0.899 & 0.990 & 0.990 & 0.987 & 0.962 \\
\hline
\end{tabular}

Note: Confidence level $\left(* *=99\right.$ percent, ${ }^{*}=95$ percent,$+=90$ percent $)$. 


\subsubsection{Cohort factors}

Birth-year-specific unobservable determinants of labor supply appear to be particularly important in Chile. These so-called cohort effects indicate that someone age 50 born in 1940 may not present the same age profile of labor supply as someone born in 1950. Cohort factors, represented by birth year correct constant age factors for changes that can affect the participation at each age (those variables are marked with 15_1975, 15_1980 and so on in Table 1 and subsequent, indicating someone born in 1975 and age 15 in 1990, the first year of the sample).

Across all ages, particularly among women, participation is strongly influenced by cohort effects likely capturing strong cultural factors that can shift the participation profile of different cohorts (Contreras and Plaza, 2010). Prime ages for labor supply (35 to 54) seem to be the most influenced. The strongest negative cohort effect is found for women born in the 1960s, entering the sample in the mid-1990s, implying that a 35 year old entering the sample after that would display a higher average labor force participation at each age. This result may suggest that the survey evidence used by Contreras, Hurtado and Sara (2012) — which finds that there is a strong negative perception of work outside the home by females - is more applicable to older cohorts. For men, cohort effects appear to be signal that, independently of age, the first cohorts entering the sample (born 1955 or 1955, for instance) show a stronger motive for participating to the labor market.

\subsubsection{Time trends}

Finally the empirical analysis shows strong and significant time trends-both linear and quadratic (trend and trend 2 in Table 1 and subsequent) - especially for women, explaining most of the recent dynamics in aggregate labor force participation rates. Strong time trends could be related to changes in policies or other social aspects which are not captured by the observable variables in our model. For women, trends have been strong and significantly positive. In the case of older women age 55 to 64 , and 65 and older, trends have been quadratic.

For men, trends are negative, albeit moderate in many cases, especially at young and old ages. In Table 3, the alternative specification with the inclusion of education enrollment in the case of men makes the time trends for young adults statistically insignificant, implying that the trend was capturing changes in the behavior towards education. Enrollment in tertiary education exhibits an increasing trend since 1990s in Chile as young adults age 15 to 24 have longer education spells, subtracting time available to supply labor. Controlling explicitly for education does not change our results in the case of women, implying that the time trends capture other types of changes such as social perceptions towards labor, something which has been suggested by other studies (Fort and others (2007) and Contreras, Hurtado and Sara (2012)).

Figure 9 and Figure 10 display the contribution of the different determinants of labor force participation, other than the age factors, in the case of men and women respectively for different age classes. Since the factors related to age are important for men, the other determinants are less important than in the case of women in explaining the dynamics of labor force participation. 
Figure 9: Factors explaining LFP rate: Men

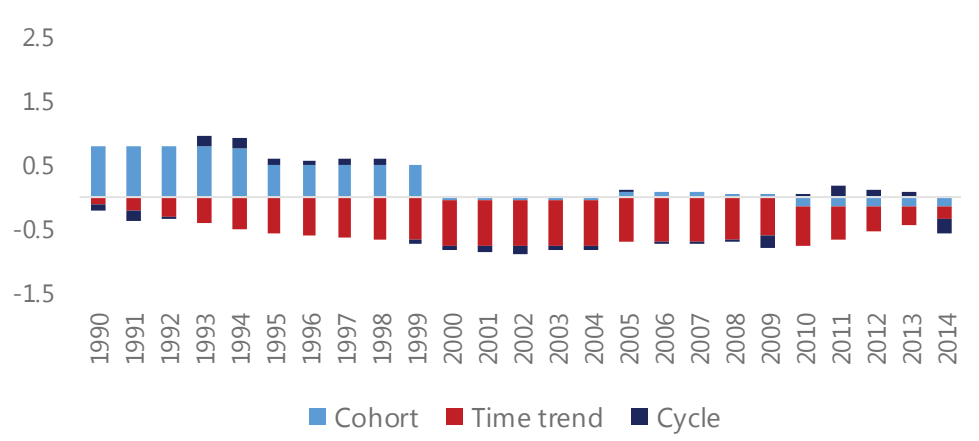

Source: IMF staff calculations. In percentage points explained

Figure 10: Factors explaining LFP rate: Women

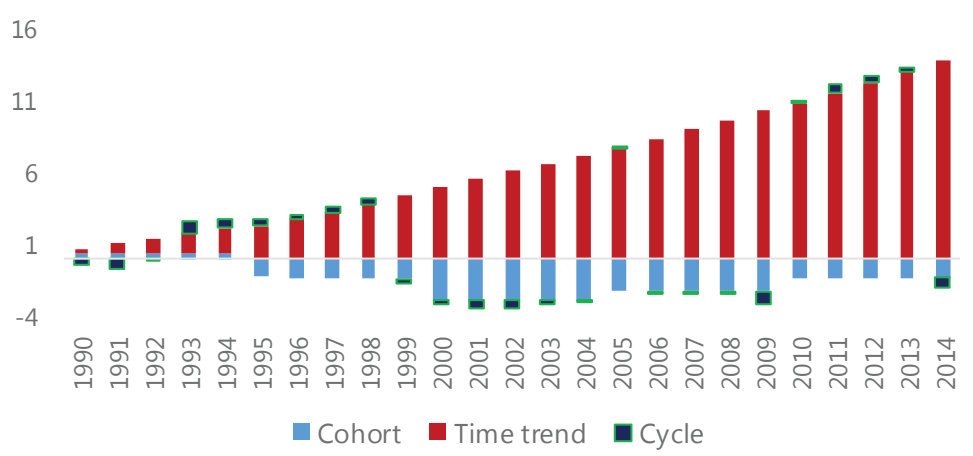

Source: IMF staff calculations. In percentage points explained

For women, steep time trends especially at prime ages explain most of the sharp increase in participation that we observe in the data. In the case of women age 25 to 34 and 35 to 54 , steady positive trends can be related to policies becoming more gender friendly, freeing more time for women from child caring or rearing, or social perceptions about female work outside the home. For instance, research has showed that the extension of the primary school hours from part time to full time starting from 1997 has had a positive impact on female labor force participation (Berthelon, Kruger and Oyarzun, 2015). The increase in the number of schools providing full-time schedules increased at a steady pace since 1997.

\section{$5 \quad$ Projection Scenarios}

Using the results from equation (1) for each age group, we can project the future dynamics of the economy-wide labor force participation rate by using groups' respective population shares and assuming that the cyclical component is zero. Using projected age-distribution 
data, cohorts follow the estimated cohort-age profile, with the assumption that each entering cohort does not experience any systematic shifts in its lifetime participation profiles relative to the last estimated cohort.

Projected values for the variables in equation (1) are obtained by using population projections from the United Nations Population and Development Database (medium-fertility scenario), IMF WEO projections for employment and output gap. For the baseline scenario, we assume that all the deterministic trends flatten out at the last observed level. In the absence of time trends, the gradual change in the age distribution of the labor force (age factor) will exert downward pressures on both male and female participation, subtracting $1 / 5$ percentage points by 2021 from aggregate participation rates (and more over the medium term). In Figure 11, panel A and B, we plot the prediction forward implied by the only age-specific constant $\alpha$ and the change in the aggregate LFP rate implied by the population dynamics for each age class (red line).

Figure 11: LFP rate projection scenarios: Baseline

Panel A. Male

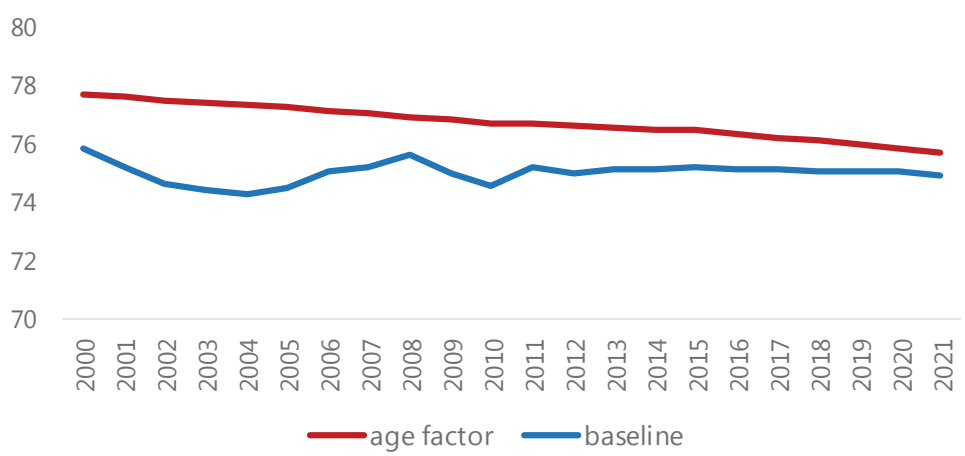

Panel B. Female

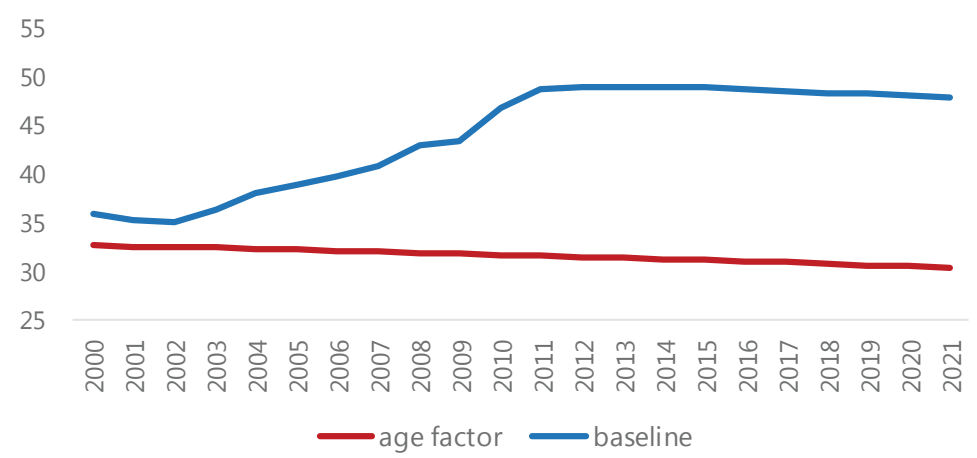

In the alternative scenarios, we construct projected paths for men's and women's par- 
ticipation by using the estimated time trends (Figure 12). In the first case (scenario 1), we assume that while men's participation rate trend is unchanged, the participation rate of women follows a linear trend similar to what was estimated during the 2000s, reaching in 2021 levels just above current OECD average of 52 percent. ${ }^{5}$ For the estimated trends over history to continue in the future, policies would play an important role. In particular, those aiming at supporting participation of women and with older women working longer as life expectancy is rising. Under this scenario 1, the labor force participation rate reaches 64 percent in 2021, from 60 percent in 2015.

Figure 12: LFP rate projection scenarios: Baseline and alternative scenarios

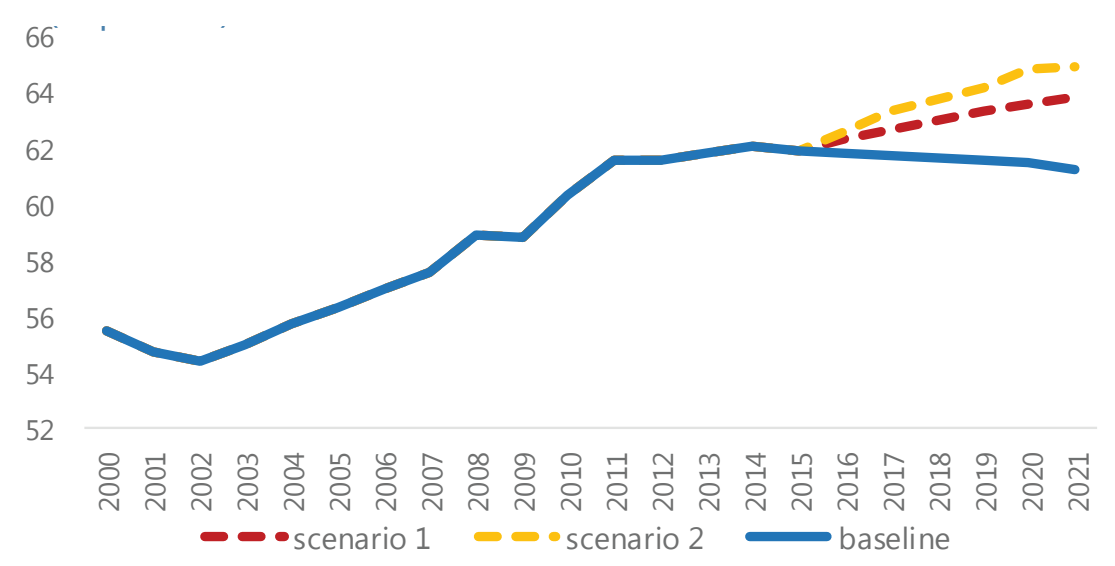

Source: IMF staff. In percent

In the other scenario (scenario 2), we assume that men's participation also improves as older workers stay longer in the labor force postponing retirement and some of the time trends of workers age 65 and older lift the aggregate participation rate. Under scenario 2, the aggregate participation rate increases to 65 percent by 2021. Using the labor share parameter (0.56) from Blagrave and Santoro (2016), the assumed increase in labor force participation growth in scenario 2 could increase potential growth by up to $1 / 4$ of a percentage point.

\section{Concluding remarks and policy discussion}

The current paper studies the forces behind the increase in labor force participation observed during the 2000s in Chile, and the subsequent deceleration since 2011. Using a cohort model, we find that while the dynamics of male labor force participation over the past decade are well explained by the aging of the population, in the case of women the effects from aging were outweighed by other, difficult to quantify cultural or policy factors. More recently, the role of these forces has weakened in the case of women, explaining most of the stagnation in the labor force participation observed in the last 5 years.

\footnotetext{
${ }^{5}$ In the estimates, female labor force participation displayed a non-linear time trend during the sample period, alongside with a linear trend. We think that assuming an exponential trend for projecting future participation would be unrealistic and will bring the participation of women well above OECD average.
} 
We also show that participation is significantly procyclical, both for men and women, at young and old ages and that birth-year-specific effects are significant with early cohorts entering the sample supplying more labor, independently of age. Different from previous literature, exploiting mainly micro-data, we do not find that enrollment in higher education affects aggregate female labor force participation but only male participation for certain age classes. Using these results, we analyze several scenarios. Under the baseline scenario, in which participation rates decline slightly as demographic headwinds prevail, the aggregate participation rate would be $1 / 5$ of a percentage point lower by 2021 .

A substantial factor capable of achieving a rise in labor supply is well-designed labor policies. In the case of women, it has been demonstrated that better-located childcare facilities which are open longer hours have a positive impact on labor force participation (Contreras, de Mello and Puentes, 2008; Berthelon, Kruger and Oyarzun, 2015). These considerations are especially important in the case of Chile, where transportation infrastructure could be a limiting factor and need to be also taken into consideration.

Contreras, Puentes and Bravo (2012) examine the hypothesis that adequate provision of childcare services, in terms of closeness and compatibility between hours of operation and labor hours, has an effect on labor force participation rates of women. Using an extensive survey designed to measure factors related to childcare, they simulate a scenario in which 50 percent of women would benefit from adequate provision of childcare and find that labor participation would increase between 1 and 8 percent.

To illustrate the importance of even modest changes in participation rates, we present several projection scenarios. In particular, we show that if participation-rate dynamics of both men and women return to recent historical positive trends, aggregate labor force participation rate can increase by up to 4 percentage points to 65 percent-above the current OECD average. The impact on potential growth would be sizable, raising potential growth by up to a $1 / 4$ percent in the medium term, relative to a scenario in which participation rates remain at current levels. 


\section{References}

[1] Aguirregabiria Victor and Andres Luengo (2015), A Microeconometric Dynamic Structural Model of Copper Mining Decisions, University of Toronto, mimeo

[2] Albagli Elias and Emiliano Luttini (2015), Expectativas, Incertidumbre, e Inversión en Chile: Evidencia Macro y Micro de la Encuesta IMCE, Mimeo Central Bank of Chile

[3] Balleer Almut, Ramon Gomez-Salvador, Jarkko Turunen (2014), Labour Force Participation Across Europe: A Cohort-Based Analysis, Empirical Economics, 46(4), pp. $1385-1415$

[4] Berthelon M., D. Kruger and M. Oyarzn (2015), The Effects of Longer School Days on Mothers Labor Force Participation, IZA Working Paper No. 9212

[5] Bils Mark and Peter J. Klenow (2000), Does schooling cause growth?, American Economic Review, 90(5), pp. 1160-1183

[6] Blagrave Patrick and Marika Santoro (2016), Estimating Potential Output in Chile: A Multivariate Filter for Mining and Non-Mining Sectors, IMF Working Paper no. 16/201

[7] Contreras D., L. de Mello and E. Puentes (2008), Encouraging Labor Force Pariticpation in Chile, OECD Working Paper n. 608

[8] Contreras Dante, Agustin Hurtado, and M. Francisca Sara (2012), La Excepcion Chilena y las Percepciones de Genero en la Participacion Laboral Femenina, Universidad de Chile Serie Documentos de Trabajo (SDT) 374

[9] Contreras Dante and Gonzalo Plaza (2010), Cultural factors in women's labor force participation in Chile, Feminist Economics 16(2), pp. 27-46

[10] Contreras Dante, Esteban Puentes and David Bravo (2012), Female Labor Supply and Child Care Supply in Chile, Working Papers wp 370, University of Chile, Department of Economics

[11] Contreras Dante and Paulina Sepulveda (2016), Effect of Lengthening the School Day on Mother's Labor Supply, Policy Research Working Paper Series 7599, The World Bank

[12] Corbo Vittorio (2014), Growth opportunities for Chile, Editorial Universitaria, Chile.

[13] Fallick Bruce and Jonathan Pingle (2007), A Cohort-Based Model of Labor Force Participation,Finance and Economics Discussion Series, Federal Reserve Board, Washington

[14] Ferrada-Borquez Luz Maria and Pilar Zarzosa Espina (2010), Participacion Laboral de las Mujeres en las Regiones de Chile, Revista Universum, no. 25, vol. 2

[15] Fort Lucia, Indu John-Abraham, Maria Beatriz Orlando, and Claudia Piras (2007), Chile: Reconciling the Gender Paradox, World Bank En Breve, April, no. 105 
[16] International Monetary Fund (IMF), 2015, Northern Spring, Southern Chills Regional Economic Outlook: Western Hemisphere, Chapter 4, April, Washington DC

[17] Larrañaga O. (2006), Participacion Laboral de la Mujer en Chile: 1958-2003, Departmento de Economia, Universidad de Chile

[18] Marcel M. and A. Naudon (2016), Transiciones Laborales Y la Tasa de Desempleo en Chile, Central Bank of Chile Working Paper n. 787.

[19] Mateo Diaz M. and L. Rodriguez-Chamussy (2013), Childcare and Women's Labor Participation: Evidence for Latin America and the Caribbean, IADB-TN-586

[20] OECD (2015), Education policy outlook 2015: Making reforms happen, OECD Publishing

[21] Pardo Lucia (1988), Una Revision Historica a la Participacion de la Poblacion en la Fuerza de Trabajo. Tendencias y Caracteristicas de la Participacion de la Mujer, Estudios de Economia, Universidad de Chile 